\title{
Respiratory Depression After Intraoperative Opioid-Containing Periarticular Multimodal Drug Injection
}

Keisuke Yoshida, MD, Yoshie Noji, MD, Norie Sanbe, MD, Hideaki Ebana, MD, Shinju Obara, MD, Masahiro Murakawa, MD The Department of Anesthesiology, Fukushima Medical University, Fukushima, Japan.

\section{BACKGROUND}

Recently, opioid-containing periarticular multimodal drug injection (PMDI) has become a common practice for pain management after artificial joint replacement surgery [1,2]. The aim of this retrospective study was to investigate the incidence of postoperative respiratory depression (RD) by examining respiratory rate $(\mathrm{RR})$ and arterial oxygen saturation $\left(\mathrm{SpO}_{2}\right)$ in the patients who received opioid-containing PMDI.

\section{Reference \\ 1. Gibbs DM et al. J Bone Joint Surg Br 2012:94:1154-9. \\ 2. Jin J et al. J Arthroplasty 2013:28:1882-7.}

\section{METHODS}

This retrospective study was approved by the Ethics Committee of Fukushima Medical University (No.2818). We examined the digital records of patients who met all of the following conditions:

1) underwent total knee or hip arthroplasty at our institution

2) received a PMDI (containing morphine 5-10 mg) during surgery

3) had their postoperative $\mathrm{RR}$ and $\mathrm{SpO}_{2}$ continuously recorded using the Nellcor ${ }^{T M}$ Bedside Respiratory Patient Monitoring System, PM1000N (Medtronic, Boulder, CO, USA)

4) received no opioid either for spinal/epidural anesthesia during surgery or for postoperative analgesia continuously intra and postoperatively

The patient information was collected from medical and anesthesia records. The incidence of RD, defined as RR $<10$ breaths/min for 5-minute or longer and/or $\mathrm{SpO}_{2}<90 \%$ for 1 minute, between the end of surgery and the morning of the first postoperative day was examined.

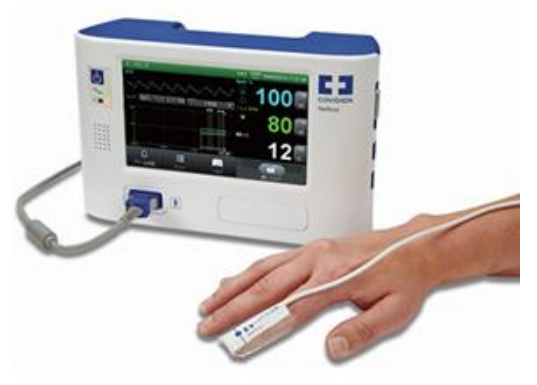

Nellcor ${ }^{\mathrm{TM}} \mathrm{PM} 1000 \mathrm{~N}$

\section{RESULTS}

We analyzed the data obtained from 23 patients. They underwent surgery under one of the following: 1) general anesthesia; 2) general anesthesia combined with epidural anesthesia; or 3) spinal anesthesia with sedation by propofol.

\section{RESULTS (cont.)}

Postoperative $R D, R R<10 /$ min without the decrease of $\mathrm{SpO}_{2}$, occurred in five of the 23 patients (22\%), 23 times in total (median 3 , range 1-10) after surgery. The median time from PMDI to RD occurrence was 180 minutes (range 70-505), and the median RD event duration was 400 seconds (range 309-1449).

\section{DISCUSSION}

1. At the time of RD occurrence, these five patients had received no respiratory-affecting medications intra- or postoperatively, other than the morphine that was included in the PMDI. This suggests an adverse effect of morphine on respiratory condition.

2. Three patients developed RD even 4 hours after PMDI. Morphine-6-glucuronide, a metabolite of morphine, might be involved in prolongation of main and side effects of morphine.

3. Limitations: This study is a retrospective study, which lacks a control group. Additionally, the number of cases in this study is too small to discuss which factors (such as surgical procedure, age, body weight, BMI, gender, ASA status, etc.) affect RD.

\section{CONCLUSION}

PMDI containing opioids can cause postoperative RD. Careful postoperative monitoring is essential to detect such conditions.

Table 1. Patient Characteristics $(n=23)$.

\begin{tabular}{lc}
\hline Gender (male/female) & $1 / 22$ \\
Age $(\mathrm{yr})$ & $65.1 \pm 9.7$ \\
Height $(\mathrm{cm})$ & $150.7 \pm 4.9$ \\
Weight $(\mathrm{kg})$ & $55.3 \pm 10.5$ \\
Body Mass Index $\left(\mathrm{kg} / \mathrm{m}^{2}\right)$ & $24.3 \pm 4.0$ \\
Surgical Procedure & \\
THA & 19 \\
TKA & 4 \\
Anesthesia Method & 4 \\
General & 4 \\
General + Epidural & 15 \\
Spinal + Propofol Sedation & \\
\hline
\end{tabular}

The values are mean $\pm S D$. THA = total hip arthroplasty, TKA = total knee arthroplasty.

Table 2. Details of five cases of respiratory depression (RD) occurrence.

\begin{tabular}{|c|c|c|c|c|c|c|c|c|c|c|c|c|c|c|}
\hline \multirow{2}{*}{ Case } & \multirow{2}{*}{ Age } & \multirow{2}{*}{ Sex } & \multirow{2}{*}{$\begin{array}{c}\text { Height } \\
{[\mathrm{cm}]}\end{array}$} & \multirow{2}{*}{$\begin{array}{l}\text { Weight } \\
\text { [kg] }\end{array}$} & \multirow{2}{*}{$\begin{array}{c}\mathrm{BMI} \\
{\left[\mathrm{kg} / \mathrm{m}^{2}\right]}\end{array}$} & \multirow{2}{*}{$\begin{array}{l}\text { Surgical } \\
\text { Procedure }\end{array}$} & \multirow{2}{*}{$\begin{array}{l}\text { RD } \\
\text { times }\end{array}$} & \multirow{2}{*}{$\begin{array}{l}\text { RD duration } \\
\text { time }[\mathrm{sec}]\end{array}$} & \multirow{2}{*}{$\begin{array}{c}\text { Time from PMDI } \\
\text { to RD [min] }\end{array}$} & \multirow{2}{*}{$\begin{array}{l}\text { Least RR } \\
{[/ / \mathrm{min}]}\end{array}$} & \multirow{2}{*}{$\begin{array}{c}\mathrm{SpO}_{2} \text { during } \\
\mathrm{RD}[\%]\end{array}$} & \multirow{2}{*}{$\begin{array}{l}\mathrm{O}_{2} \text { administration time } \\
\text { from PMDI [min] }\end{array}$} & \multicolumn{2}{|c|}{ Analgesic drugs used } \\
\hline & & & & & & & & & & & & & during surgery & after surgery \\
\hline 1 & 46 & $\mathrm{~F}$ & 154 & 58 & 24.3 & THA & 10 & $319-812$ & $107-505$ & 4 & $92-100$ & - & Ace, Flu & Flu, Pen \\
\hline 2 & 83 & $\mathrm{~F}$ & 141 & 46 & 23.0 & THA & 1 & 344 & 70 & 6 & $98-100$ & - & Flu, Fen & - \\
\hline 3 & 75 & $\mathrm{~F}$ & 150 & 39 & 17.1 & THA & 7 & $369-1449$ & $81-244$ & 4 & $100-100$ & 304 & Flu, Ace & Flu \\
\hline 4 & 66 & $\mathrm{~F}$ & 154 & 54 & 22.6 & THA & 2 & $309-315$ & $92-118$ & 4 & $99-100$ & 741 & Flu & Ace \\
\hline 5 & 60 & $\mathrm{~F}$ & 156 & 47 & 19.3 & THA & 3 & $319-682$ & $250-277$ & 4 & $100-100$ & 286 & Flu, Ace & Ace \\
\hline
\end{tabular}

In these all 5 case, the contents of the PMDI were morphine $(5 \mathrm{mg})$, ropivacaine, and epinephrine. In Case 1 , intramuscular injection of pentazocine (15 mg) was performed twice, but at 3 hours or more after RD. In Case 2, intravenous injection of fentanyl (25 $\mu \mathrm{g})$ was performed at the end of the surgery. THA = total hip arthroplasty, Ace $=$ Acetaminophen, Flu = Flurbiprofen Axetil, Pen $=$ Pentazocine, Fen $=$ Fentanyl.

$\mathbf{R R}(/ \min )$

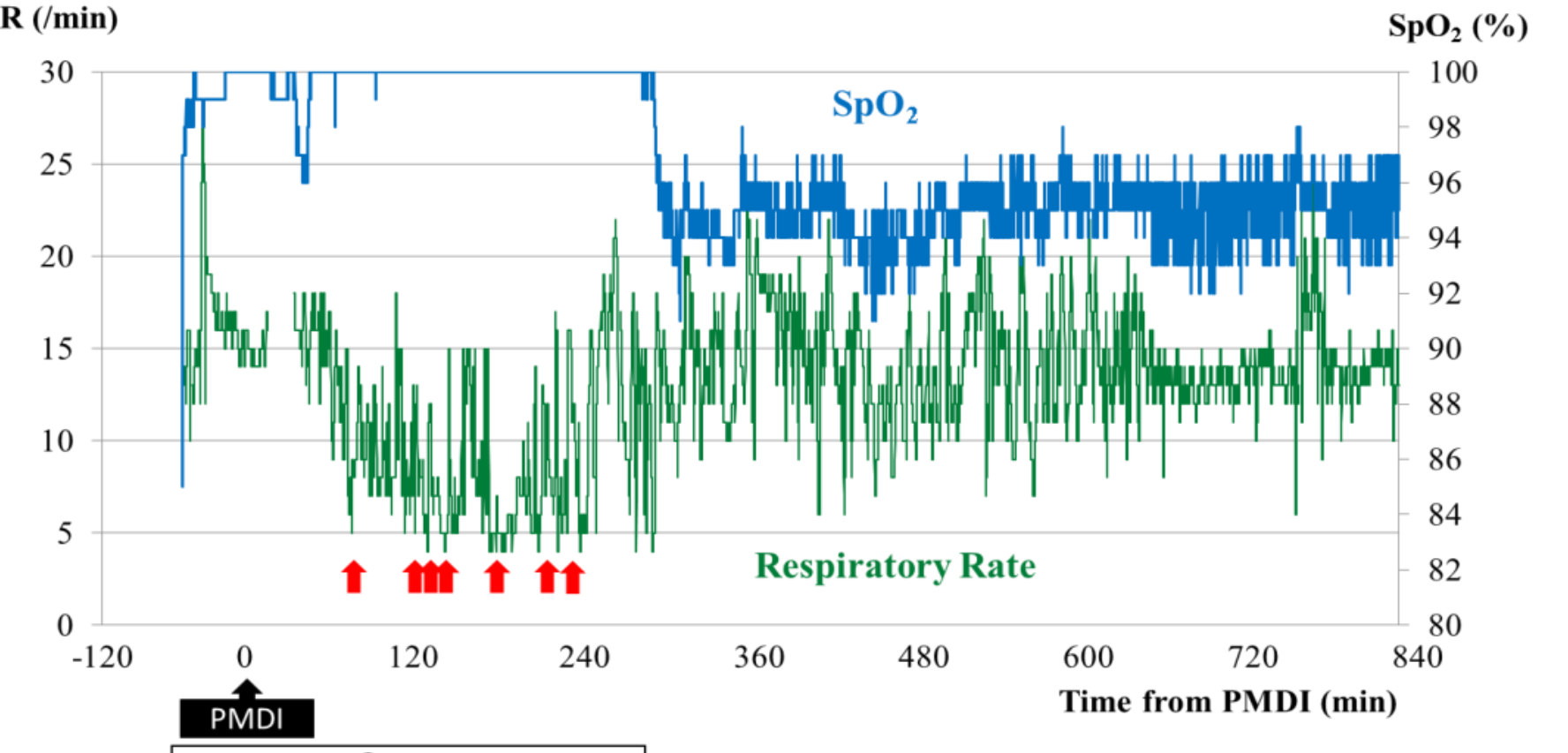

Propofol

Flurbiprofen Axetil Acetaminophen

\section{Fig. 1. The RR and $\mathrm{SpO}_{2}$ trend in a representative case of} postoperative RD.

A 75-year-old woman (Height: $150 \mathrm{~cm}$, Weight: $39 \mathrm{~kg}$ ) received THA under spinal anesthesia (isobaric bupivacaine $12.5 \mathrm{mg}$ ) with propofol sedation. PMDI (morphine $5 \mathrm{mg}$, ropivacaine $150 \mathrm{mg}$ and epinephrine $0.15 \mathrm{mg}$ ) was administered during surgery. She left the operating room 52 minutes after PMDI, at which point she was awake and her RR was 15 breaths $/ \mathrm{min}$.

RD occurred 7 times, 81 to 244 minutes after PMDI. (The red arrows in the figure indicate the RD phases.) There was a phase in which the RR was 4-6 breaths/min lasting for 364 seconds, while $\mathrm{SpO}_{2}$ remained at $100 \%$. The only other drugs used for postoperative analgesia were flurbiprofen axetil and acetaminophen. 